\title{
Numerical and Experimental Investigation of Sonotrode for Formation of Piezocomposite Functional Elements
}

\author{
Amer SODAH*, Arvydas PALEVICIUS**, Giedrius JANUSAS***, Paulius PALEVICIUS****, \\ Yatinkumar PATEL***** \\ *Kaunas University of Technology, Faculty of mechanical engineering and Design, Studentu str. 56, 51424 Kaunas, \\ Lithuania, E-mail: amer.sodah@ktu.lt \\ **Kaunas University of Technology, Faculty of mechanical engineering and Design, Studentu str. 56, 51424 Kaunas, \\ Lithuania, E-mail: arvydas.palevicius@ktu.lt \\ ***Kaunas University of Technology, Faculty of mechanical engineering and Design, Studentu str. 56, 51424 Kaunas, \\ Lithuania,E-mail: giedrius.janusas@ktu.lt \\ ****Kaunas University of Technology, Faculty of mathematics and natural science, Studentu str. 50, 51368 Kaunas, \\ Lithuania, E-mail: paulius.palevicius@ktu.lt \\ *****Kaunas University of Technology, Faculty of mechanical engineering and Design, Studentu str. 56, 51424 Kaunas, \\ Lithuania, E-mail: y.patel@ktu.lt
}

crossref http://dx.doi.org/10.5755/j01.mech.25.6.24793

\section{Introduction}

Microelectromechanical systems and microsensors have proven to be a key driving technological factors in transportation, communications, health care, biotechnologies, consumer products, and other areas of science and technology. Various fabrication technologies are employed for manufacturing of micro and nano structured surfaces. Electron beam lithography, photolithography, stereolithography, and laser-micromachining are the driving technologies used for the fabrication of microstructures. But even more important are efficient and cost-effective replication methods [1-3].

Hot embossing [4] is a microstructure formation method, utilized for imprinting microstructures on a substrate, utilizing preheated ace form. It comprises from following advances. Polymer is being preheated to polymer glass progress temperature, this reduces the power, required to disfigure the polymer. At that point, the polymer is being imprinted with the ideal engraving with specific imprinting power, at the temperature, under which it acts as a liquid. Finally, the form is being withdraw from the polymer [5].

It is important to consider potential risk of potential deformities of the microstructure that can happen because of the dissolving of the material and withdrawal of the shape from the surface of polymer. Most normal imperfections incorporate material shrinkage, rises of lingering gas, which stay inside the polymer after the procedure, inadequate filling proportion of the mould form shape, high surface harshness, non-uniform shape engraving, breaks (for the most part due to bond among form and polymer) and so on [611]. Lacking filling proportion of microstructure, for example master isn't being recreated correctly as indicated by its shape, causes lower diffraction efficiency.

Most important point, which impacts the nature of imprinted microstructure are temperature, pressure and time of process [12-14]. High frequency excitation is another contributor, which, when appropriately misused can fundamentally improve results of the procedure. Ultrasonic excitation can be applicable for various purposes. It is broadly connected in welding, replicating and joining of thermoplastic materials with low relaxing temperature [15-18]. In these procedures ultrasonic energy is changed over into heat through the wonders of intermolecular erosion inside the thermoplastics [19]. The produced heat liquefies thermoplastics, makes the soften stream and fills the interface between master mold and polymer surfaces.

A few products with a fine surface structure on the micrometer to nanometer scale have been created; their utilization in numerous fields is incredibly foreseen. In the medicinal field, regenerative restorative methods have been proposed utilizing tissue platforms with a fine nanostructure $[20,21]$. Physiological sensors utilizing surface plasmons have been developed [22]. Also, in the semiconductor and electronics segment fabricating fields, advancement of a transistor, memory, and sensor utilizing scaling down and carbon nanotubes as wiring for CPUs is advancing [23]. New designed media for high-thickness memory for information stockpiling are additionally being considered [24]. Moreover, a nanostructure on the outside of a movie with cutting edge highlights of an electrolyte film has been created for use in the vitality field of polymer electrolyte power modules (PEFCs) and direct-methanol energy components (DMFCs) [25,26]. These products not just have microscale and nanoscale surface structures, they likewise offer extra esteem and execution.

High frequency vibrations are generally utilized in various applications and innovations. capillary waves are utilized for bead development on a vibrating surface in [27]. Surface acoustic waves are utilized to concentrate bioparticle suspensions [28], to control the temperature of fluid beads [29], to create single heartbeats and breaks [30], to deliver standard, long-run, spatially requested polymer designs without requiring the utilization of physical or concoction templating [31]. Ultrasonic motors are utilized to drive liquids [32], to help heart pressure devices, to control electro-rheological liquids [33].

VAPs (Vibroactive Pads) are developed and fabricated for the thermal imprint process; they operate is based on inverse piezoelectric effect, i.e. converting $\mathrm{AC}$ voltage to harmonic mechanical displacements. The purpose of a VAP is to stimulate the flow of pre-heated polymer towards the master microstructure and enhance replicability. 
The objective of the VAPs device is to generate uniform vibratory displacements at every point of the top operating surface Fig. 1. The ODS (operating deflection shape) ensures uniform beneficial influence of the high-frequency vibratory excitation throughout the entire surface of the replicated microstructure.

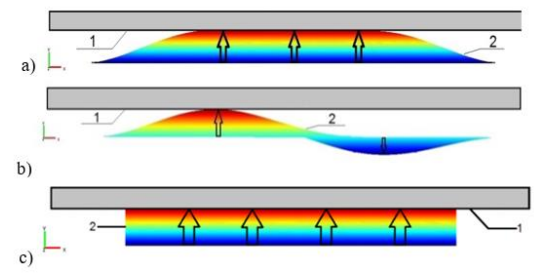

Fig. 1 Contact patterns between the VAP (vibroactive pads) 2 and the polymer 1: the first ODS of the membrane (a), the second ODS of the membrane (b) and the ODS (operating deflection shape) when the operating surface is in full contact with the polymer (c) [34]

Single layer vibroactive pad (Fig. 1) is not able to generate large displacements, what in turn diminishes the effect of high frequency excitation, because lower force forces polymer to flow. As shown in Fig. 1a first mode of vibration shows the full contact with the polymer and Fig. $1 \mathrm{~b}$ shows the second mode of vibration which does not cover the entire surface of the polymer for the imprinting so it will not produce good quality of the imprinting of microstructure. To take care of recently referenced issues vibroactive pad, in light of the multilayer sonotrode is proposed. This kind of actuator is situated in the middle point of sonotrode, this blocks spaces, which rise under the action of mechanical load.

As per hypothesis multilayer, in view of a few layers of piezoceramic added to each other can produce greater removals and powers, than single layer can do [35-36]. Along these lines it powers preheated sonotrode to stream all the more quickly and better fill of the master structure to the polymer. The first vibration mode will be applied during the mechanical hot imprinting. This mode causes better and increasingly symmetric printing of the microstructure.

The main principle of this article is to propose a microstructure replication technique that would utilize a sonotrode to build the quality of microstructure replication process. A sonotrode generally comprises of a stack of piezoelectric transducers joined to a metal bar. The end of the pole is connected to the working material. An alternating current of the ultrasonic frequency is connected to the piezoelectric transducers and it makes them extend and contract. The frequency of the current is picked to be the resonant frequency of the apparatus, so the whole sonotrode becomes a half-wavelength resonator, vibrating longwise with standing waves at its resonant frequency. The principle elements of the sonotrode are transmission of vibration energy, force, and amplitude, and moulding of the workpiece while the material is malleable. The sonotrode must be structured and created with extraordinary consideration, because only a design that impeccably addresses the issues of the workpiece can ensure great outcomes. In case the sonotrode is inadequately developed (unacceptable frequency, transformation and amplitude) this may make the transducer break.

In this article we propose a design, computational and experimental verification of the sonotrode, that is employed in the replication process of microstructures and show that introduction of high-frequency oscillations to the replication process by the means of the sonotrode results in increased quality of replication process. Also, the applicability of high frequency sonotrode in mechanical hot imprinting process is presented. Finally, results are presented, and outcomes are discussed.

\section{Design of sonotrode}

Increase in the quality of the replication process is the primary objective of this article and is achieved by introducing high-frequency oscillations to the replication process by the means of the sonotrode. The primary function of the sonotrode is to transmit normal to surface mechanical vibrations to the formable poly-carbonate material. In this article we propose a design of such sonotrode, as well as its computational and experimental verification.

The schematic diagram of the proposed sonotrode is given in Figs. 2-3. The front mass that has a master periodical microstructure on its bottom side. The length of all edges of the front mass are equal $22 \mathrm{~mm}$ and it is made of stainless steel. The conical heating element used to heat the front mass to the desired temperature. It is placed in the middle of the front mass and is connected to it using a M5x40 screw. The diameter of the heating element is $11 \mathrm{~mm}$, length is $52 \mathrm{~mm}$ and it is made of stainless steel. A stack of six $\mathrm{PZT}-5 \mathrm{H}$ rings is shown in part c. The outer diameter of PZT$5 \mathrm{H}$ rings is $22 \mathrm{~mm}$, inner diameter is $10 \mathrm{~mm}$, and thickness is $5 \mathrm{~mm}$. And on top of them is a stainless-steel ring with outer diameter equal $22 \mathrm{~mm}$, inner diameter $-6 \mathrm{~mm}$, and thickness $-5 \mathrm{~mm}$. The stainless-steel ring is connected to front mass using a M5x40 screw. The stack of six piezoceramic rings are used to induce the higher vibrations and to reduce the time of replication process.

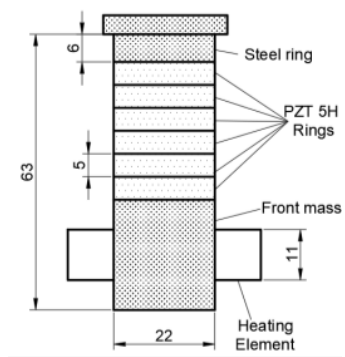

Fig. 2 Drawing model of the designed sonotrode

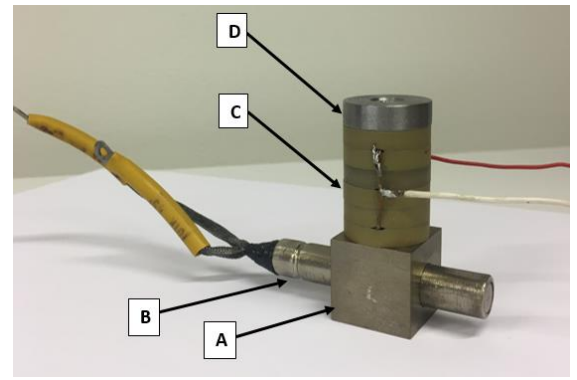

Fig. 3 Photo of the designed sonotrode: A - front mass, B heating element, $\mathrm{C}$ - piezoceramic rings, $\mathrm{D}-$ steel ring

The primary function of the sonotrode is to transmit sound energy (mechanical vibrations) produced by the Stack of multilayer PZT rings, to the workpiece. It transfers the vibrations to the plastic component. If needed, it is possible to install a booster on the PZT ring stack or possible to 
increase the number of PZT rings in order to increase the amplitude of the ultrasonic waves. The material properties of the sonotrode are presented in Table 1.

Table 1

Material properties of the sonotrode

\begin{tabular}{|c|c|c|}
\hline Property & Stainless steel & Piezoceramic \\
\hline Young's modulus, $E$ & $200 \times 10^{9} \mathrm{~Pa}$ & ----- \\
\hline Poisson's ratio, $v$ & 0.33 & 0.31 \\
\hline Density, $\rho$ & $7850 \mathrm{~kg} / \mathrm{m}^{3}$ & $7600 \mathrm{~kg} / \mathrm{m}^{3}$ \\
\hline Piezoelectric constant, $d_{33}$ & ------ & 750 \\
\hline Coupling coefficient, $K_{33}$ & ----- & 585 \\
\hline
\end{tabular}

The three main parts of the Sonotrode device will be assembled orderly. The assembling of the Sonotrode device will be done by making use of the long screw. The standard screw has been selected and inserted. The long screw is placed in the middle of the device. It will be at the bottom of the heating plate.

\section{Simulation and experimental verification of sonotrode}

In order to exploit all the potential of the designed sonotrode it is necessary to get highest displacements at the vibration frequency. This is only possible when sonotrode works under first resonant frequency. In order to find the resonant frequency numerical simulations must be performed.

Firstly, for the numerical simulation COMSOL Multiphysics 5.4. package is used to find eigenfrequency of the system and further experimental analysis by using impedance analysis experiment.

Prepared numerical model in COMSOL Multiphysics 5.4 is presented in Fig. 4.

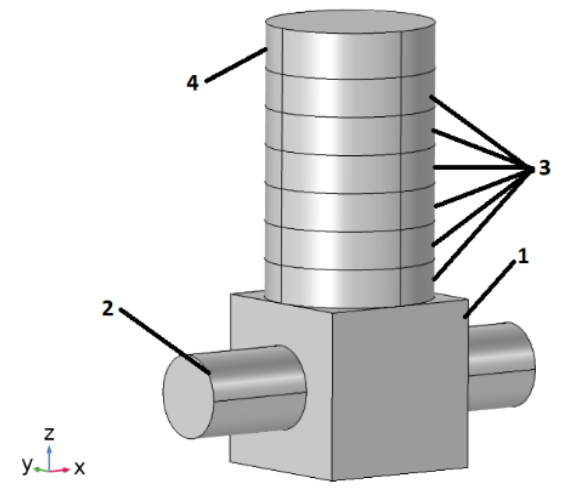

Fig. 4 Numerical model of sonotrode design in COMSOL 5.4. consist of front mass 1 , heating element 2 , six PZT $5 \mathrm{H}$ rings 3 , and top stainless-steel ring 4

An unstructured tetrahedral mesh is used for all parts of the sonotrode. Piezoelectric devices physics interface is used for computational simulation which combines solid mechanics and electrostatics together with the constitutive relationships required to model piezoelectric effects. In this simulation inverse piezoelectric effects are modelled according to [37] and the piezoelectric coupling is formulated using a stress-charge form. Coupled physics governing equations are as follows:

$$
\rho \frac{\partial^{2} u}{\partial t^{2}}-\nabla \cdot \sigma=F v
$$

$\nabla \cdot D=\rho v$,

$$
\sigma=c_{E} S-e^{T} E,
$$

$$
D=e S+\varepsilon s . E,
$$

where: $u$ is the field of displacement; $t$ is time; $\rho$ is the density of the material; $s$ is the stress tensor; $F$ is an external volume force; $D$ is electric displacement or electric flux density; $v$ is velocity and $\rho v$ is charge density in vacuum; $S$ is strain; $E$ is electric field; $c E$ is elasticity matrix; e is coupling matrix; $e$ is permittivity matrix.

The fixed constraint condition that makes the geometric entity fixed (the displacements are zero in all directions) is applied to the top surface of stainless-steel ring of the sonotrode. In addition, a condition of the zero charge at exterior boundaries is applied:

$$
-n \cdot D=0 \text {. }
$$

In time-dependent simulation a potential difference between the top and bottom surfaces of the piezoceramic rings is applied:

$$
V=A \sin (2 \pi f t),
$$

where: $A$ is amplitude and $f$ is frequency of the oscillations. This gives rise to an electric field parallel to the poling direction and thus induces periodic deformations of PZT-5H rings.

To ascertain that a periodic excitation causes a resonance, eigenfrequency analysis of the sonotrode was performed.

Operating frequency from the numerical simulation is obtained in $\mathrm{khz}$ and the displacement of the model in the relative direction in $\mathrm{mm}$.

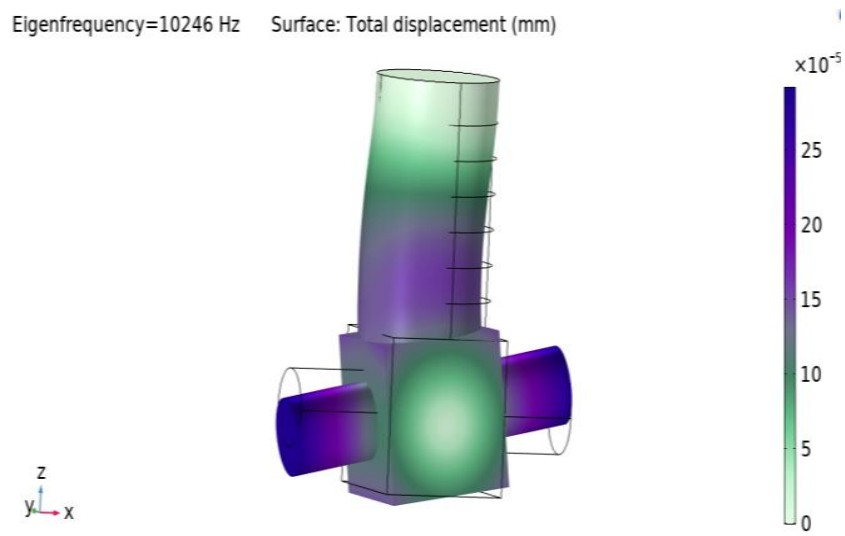

Fig. 5 Result of numerical simulation of sonotrode at frequency $10.245 \mathrm{kHz}$

The displacement of the sonotrode at frequency of $10.245 \mathrm{kHz}$ is presented in the Fig. 5. When model of the sonotrode is excited at $10.245 \mathrm{kHz}$ the obtained shape of the displacement is not shown as the desire mode of deformation.

Achieved deformed shape and the displacement of the numerical results at the frequency $11.223 \mathrm{kHz}$ is shown in Fig. 6. The displacement of the sonotrode is aligned to $\mathrm{z}$ 
axis. This means the model is in agreement with the required movement for the hot imprinting process. The sonotrode is moved in upward and downward direction at frequency of $11.223 \mathrm{kHz}$.

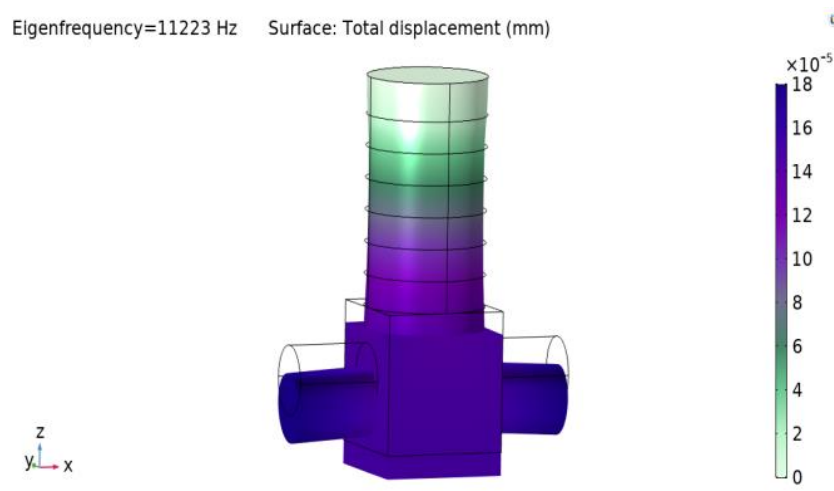

Fig. 6 Result of numerical simulation of sonotrode at Frequency $11.223 \mathrm{kHz}$

Presented graph in Fig. 7 is obtained from the COMSOL Multiphysics for the simulated numerical model of the sonotrode. In the graph it is clearly shown that the resonance frequency of the designed model of the sonotrode is $11.223 \mathrm{kHz}$. The highest peak point of the graph line is at $11.223 \mathrm{kHz}$ and maximum displacement of the sonotrode archived at same frequency is $0.115 \mathrm{~mm}$. Therefore, from the graph it is possible to state that the resonance frequency of the designed model of the sonotrode is $11.223 \mathrm{kHz}$ and the obtained displacement and the mode of deformation also represents the required mode of deformation it is possible to use the achieved frequency for the hot imprinting process.

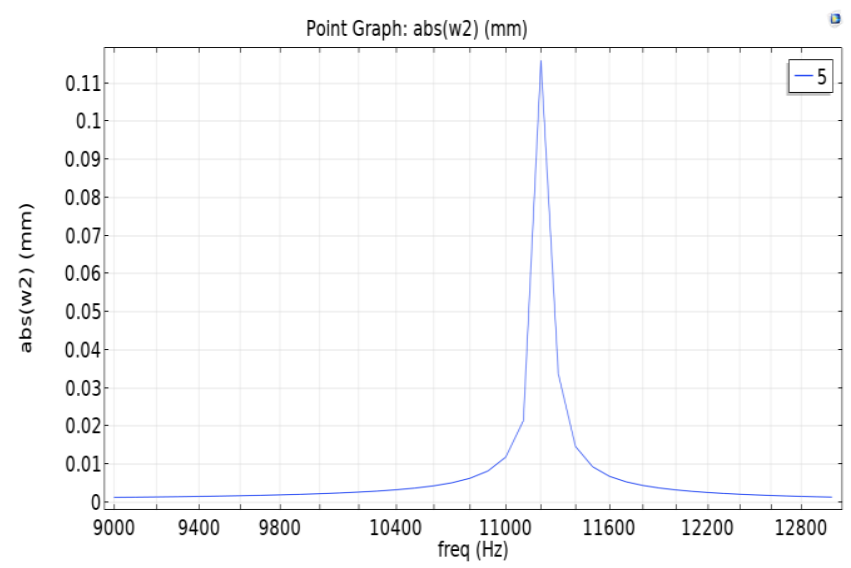

Fig. 7 Frequency displacement curve (resonance frequency of the numerical model)

In order to verify the simulation results and validate the model the impedance analysis was performed to estimate the resonance frequency of the sonotrode and its experimental value.

For determination of the working regimes the impedance analysis at different conditions was performed. Fifteen Fifteen different experiments with periodically excited and mechanically-thermally prestressed sonotrode were performed. For the experiment three different loads $(0 \mathrm{kPa}$, $7.7 \mathrm{kPa}$ and $12.5 \mathrm{kPa})$ and five heating conditions $\left(0^{\circ} \mathrm{C}\right.$, $80^{\circ} \mathrm{C}, 100^{\circ} \mathrm{C}, 130^{\circ} \mathrm{C}$ and $160^{\circ} \mathrm{C}$ ) were selected according to the usual thermal replication process of periodic microstructures.
The experimental setup of the impedance analysis measurement of sonotrode is presented in the Fig. 8. It consists of BGI mark - 10 force gauge 1 , force gauge controller 2, 6500B series of precision impedance analyser (3), designed sonotrode 4 , and Testo 845 - infrared temperature measuring instrument).

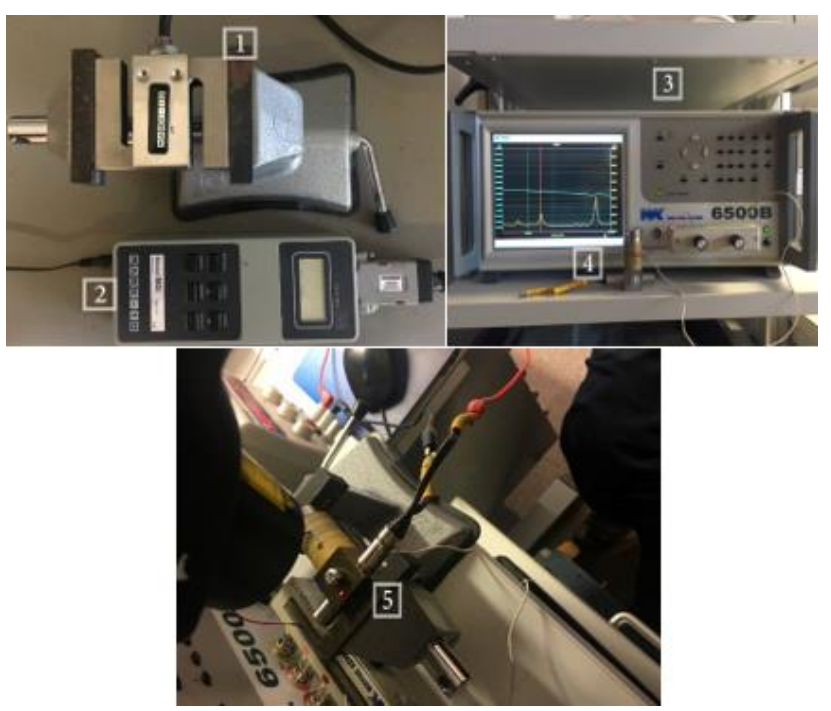

Fig. 8 BGI mark-10 force / torque gauge 1, force gauge reader $2,6500 \mathrm{~B}$ series of precision impedance analyzers 3 , sonotrode 4 , Testo 845 - infrared temperature measuring instrument 5

Because Impedance is an AC property, it cannot be easily measured like resistance. Connecting the sonotrode across the input or output of an amplifier only indicates the DC resistance. It is quite possible however to measure input and output impedance at any frequency using a signal generator, an oscilloscope (or AC voltmeter) and a decade resistance box or a variable resistor. For impedance measurement the sonotrode was connected to 6500B series of Precision Impedance Analyzers device using the wires connected to piezo ceramic rings in order to provide precise and fast testing of components at frequencies up to $120 \mathrm{MHz}$ which were applied using waveform generator \& Liner amplifier. Temperature was measured using Testo 845 - Infrared temperature measuring instrument. Temperature is applied and regulated by the voltage device in order to reach the $150^{\circ} \mathrm{C}$ with the voltage of $16 \mathrm{~V}$. The pressure was measured throw BGI mark-10 force / torque gauge which covers a variety of force measurement and torque measurement applications in order to reach $12.5 \mathrm{kPa}$. the Fig. 9.

Results of the impedance analyses are presented in

After performing the impedance analysis of the sonotrode the following results from the experiments were obtained: The resonant frequency of the sonotrode is achieved $12.69 \mathrm{kHz}$ at $160^{\circ} \mathrm{C}$. Also, during the measurement it is observed that resonant frequency has direct relation with the applied loading conditions, and it is possible to state that the higher load induces the higher frequency.

From the experimental results and simulation results it is possible to state that the both results are corresponding to each other. From the experimental study the obtained frequency is 12.69 and from the numerical simulation obtained frequency is $11.223 \mathrm{kHz}$. The difference between both the frequencies is $12 \%$. 


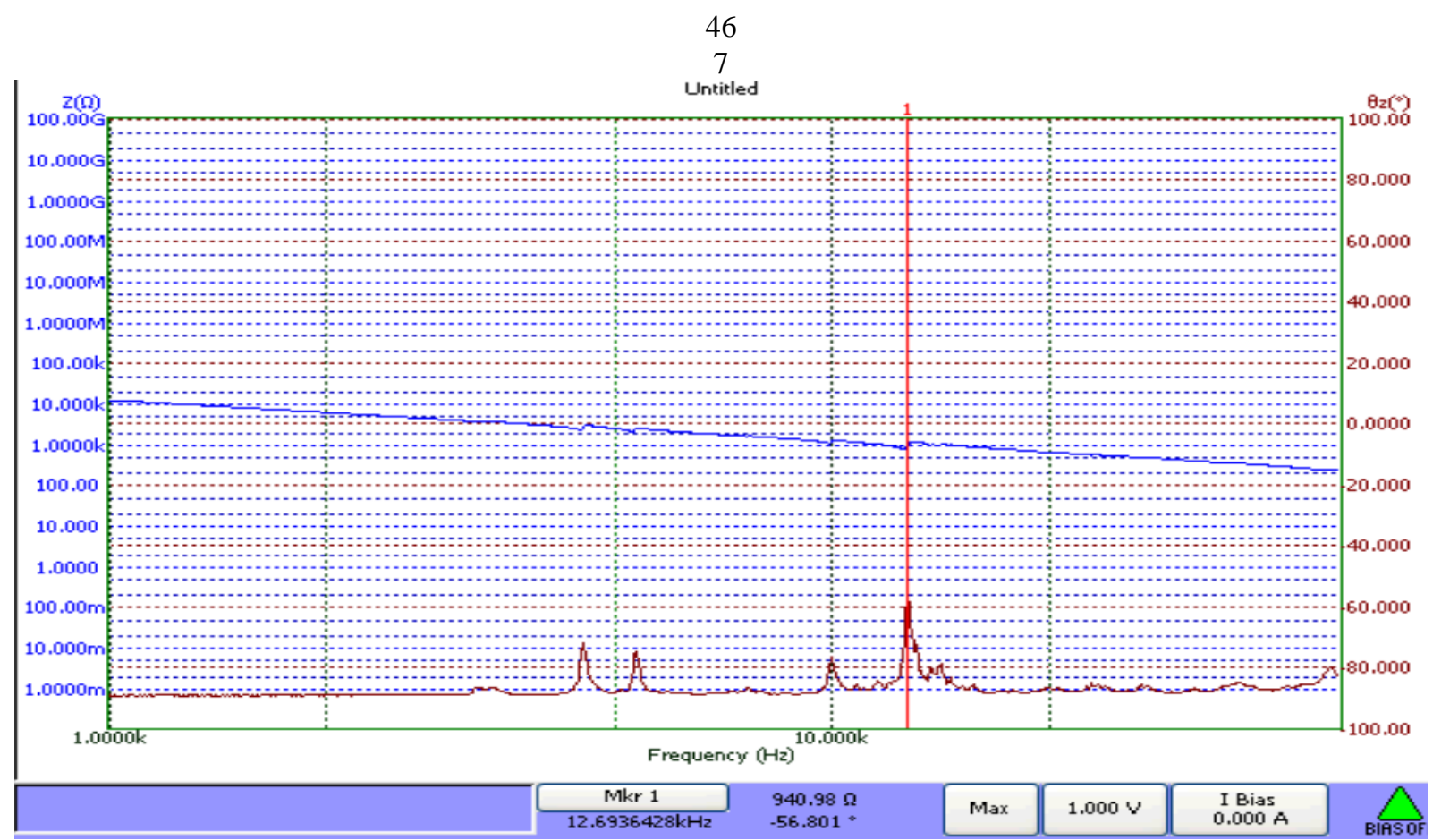

Fig. 9 Impedance analysis of the prestressed sonotrode (frequency $12.69 \mathrm{kHz}$ at $160^{\circ} \mathrm{C}$ )

\section{Temperature distribution test}

Temperature distribution test is done because it is necessary to know the thermal distribution of temperature over all parts of the sonotrode. While applying the different range of temperatures on the sonotrode we should know the exact temperature distribution on the surface of sonotrode for identifying the influence of temperature in order to increase the quality of the imprint process. So, the thermal imaging camera used to identify temperature distribution on the surface of sonotrode.

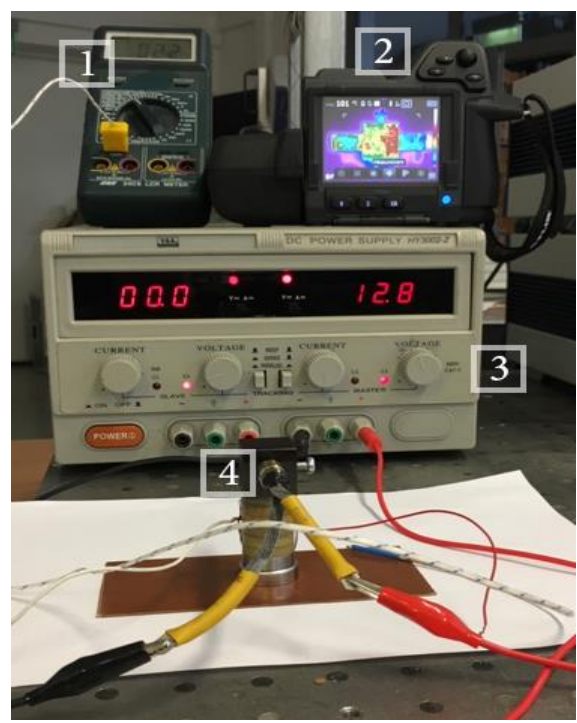

Fig. 10 Thermometer 1, FLIR T450SC thermal imaging cameras 2 , power supply 3 , sonotrode 4

The experimental setup of the temperature distribution test consists of the multi-meter to measure the temperature so it will act as a thermometer, FLIR T450SC thermal imaging camera for capturing the image to analyse the thermal distribution of the temperature over whole surface of the sonotrode, DC power supply which is directly connected with the sonotrode for applying the heat, and sonotrode. So, experimental setup is presented in the Fig. 10.

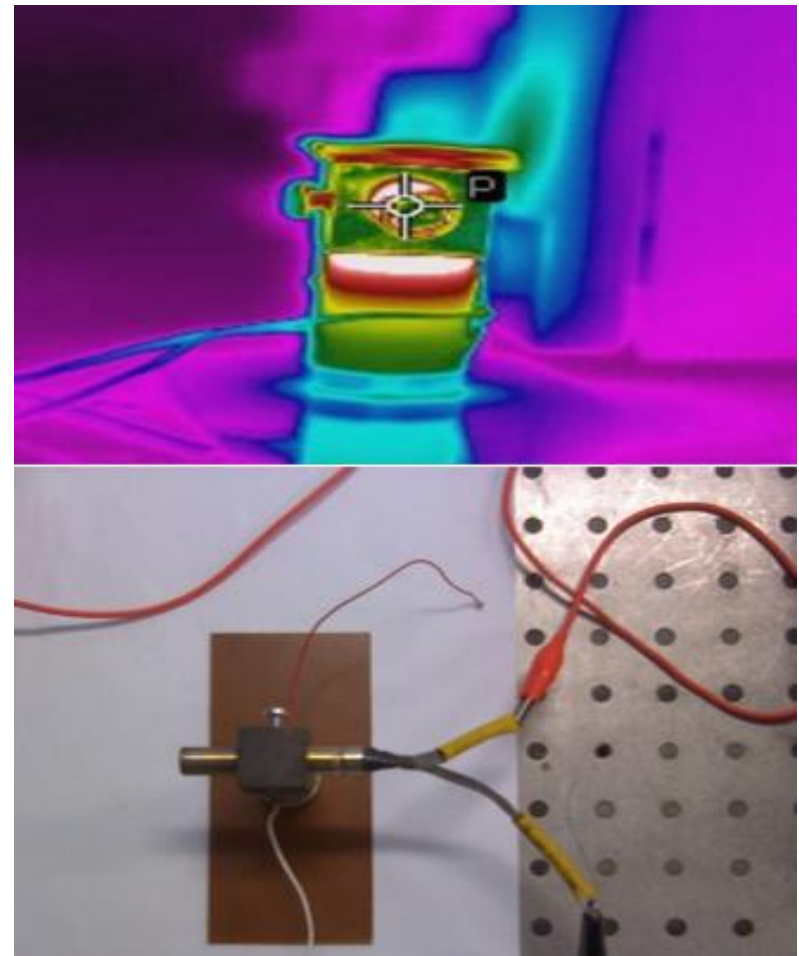

Fig. 11 Experiment results with FLIR T450 SC thermal imaging cameras for the designed sonotrode when temperature is $150^{\circ} \mathrm{C}$

The FLIR T450SC thermal camera contains tiltable IR that unit gives you great flexibility and allows you to conduct your experiments fast and in a comfortable position. Un-cooled Vanadium Oxide (VoX) microbolometer detector that produces thermal images of $320 \times 240$ pixels. Generate crisp and clear detailed images that are easy to interpret, resulting in reliable imaging with high accuracy. Equipped with 3.1 MP visual camera. 3.5" $(320 \times 240)$ LCD touch screen keeps onscreen temperature data upright in portrait or landscape.

The experimental results of thermal distribution is presented in Fig. 11 when heating element is connected to a 
DC voltage of $12.7 \mathrm{~V}$ and temperature reached $150^{\circ} \mathrm{C}$, we can see the heating element function well and the heat is distributed on the bottom part of the front mass.

During the thermal analysis of the sonotrode variety of temperature $\left(100^{\circ} \mathrm{C}, 125^{\circ} \mathrm{C}, 130^{\circ} \mathrm{C}\right.$, and $\left.150^{\circ} \mathrm{C}\right)$ has been measured however it was found that temperature of $150^{\circ} \mathrm{C}$ result in equal distribution on the whole surface of the front mass which is required for the hot imprinting of microstructure to the polycarbonate material.

\section{Experimental setup of mechanical hot imprinting}

In this section we present the results of the experiments of high-frequency vibratory assisted thermal imprint process. The influence of application of the sonotrode to the replication quality of periodic microstructures is investigated.

The experimental setup of mechanical hot imprinting with high excitation vibration frequency consist of
Tinius Olsen pressing machine for the constant and automatic operating system which is helping to provide equal distribution of the applied load for the hot imprinting. The sonotrode with the stack of PZT 5H rings for the heats up the microstructure at desired temperature of printing and produces the high frequency vibration for the batter quality of printing process. Wave form generator and power supply used to generate high frequency vibration in multi-stack sonotrode. Voltage generator is used to apply direct current to the conical heating element which is fixed in the bottom front mass for the generation of higher temperature for imprinting. Computer system is used to operate the automatic compression machine to set the parameter such as pressure, auto reverse, etc. Non-contact type temperature measuring Testo 845 - Infrared temperature measuring instrument is used to measure the temperature of the surface of the bottom side of the front mass.

The experimental setup of the mechanical hot imprinting with high excitation frequency is presented in Fig. 12.
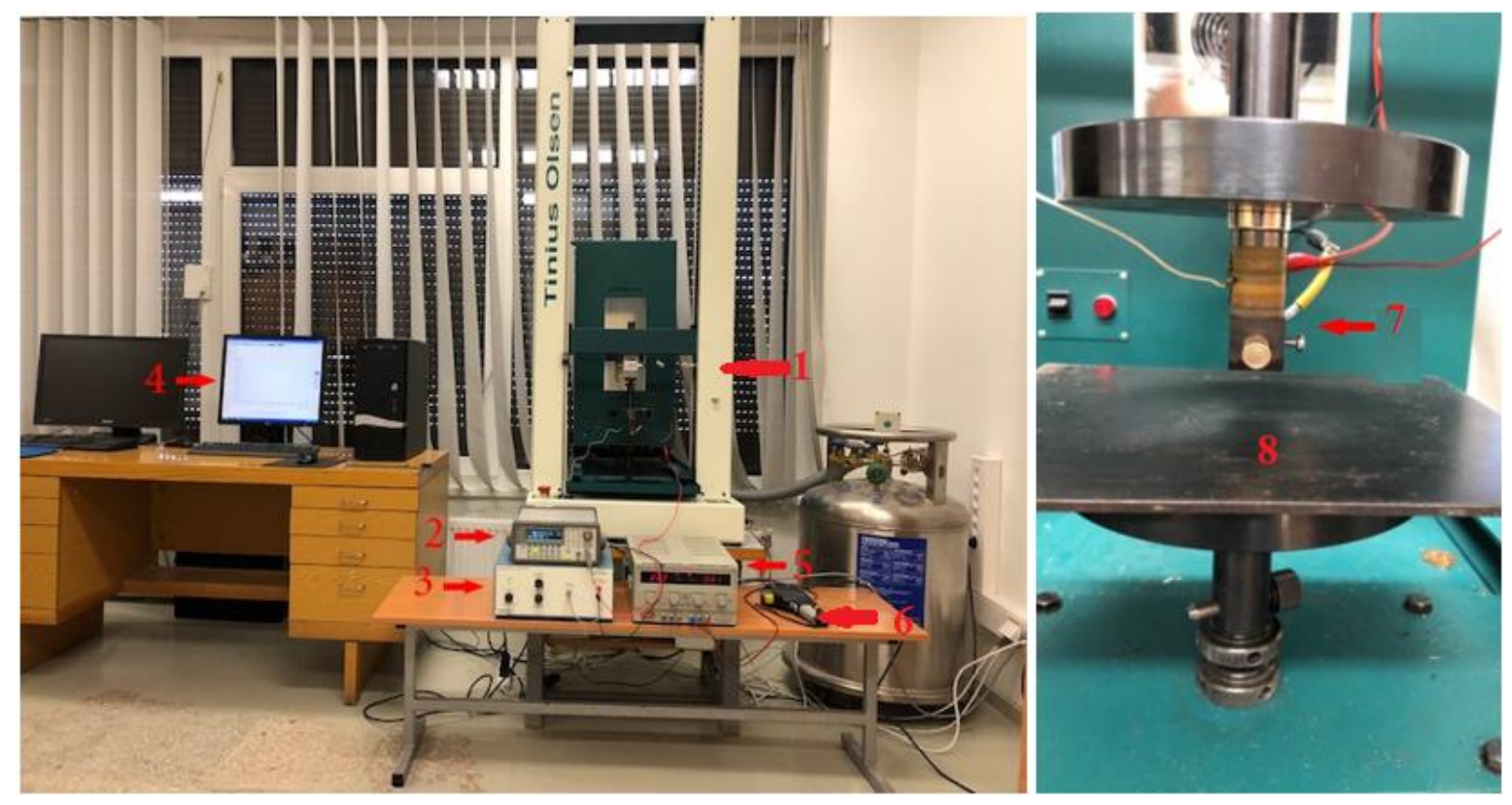

Fig. 12 The experimental setup of the mechanical hot imprinting with high excitation frequency consists of : Tinius Olsen automatic pressing machine 1, Wave form generator 2, Power Supply 3, Computer system for operating the pressing machine 4, DC voltage generator 5, Temperature measurement instrument (Testo 845 - Infrared temperature measuring instrument) 6 , Vertically fixe sonotrode 7 , Fixed base for specimen hot imprinting 8

The process of hot imprinting consists of the following steps. In the preheating stage, the temperature of the front mass and heating element is $20^{\circ} \mathrm{C}$ (the room temperature). Then preheat the front mass at $150^{\circ} \mathrm{C}$ with the help of the DC power supply and wait until it reaches the desire temperature. The temperature has been measured through the thermometer confirms the desire temperature. The heating temperature has been chosen $150^{\circ} \mathrm{C}$ because this temperature corresponds to glass transition temperature of polycarbonate. the polymer leaves glassy or brittle state and starts to be reversibly and irreversibly deformed under the action mechanical stress. In other words, it becomes viscoelastic. Imprinting of microstructure on the polycarbonate material. With help of computer system which is used to operate the pressing machine and to apply the pressure of $5000 \mathrm{~N}$ for the imprint of microstructure. The microstructure has been placed on the bottom side of the heated front mass as shown in the Fig 13. Polycarbonate material has been placed on the fixed base of pressing machine. Then the hot printing process has been started. The chosen pressure is applied for time period of $10 \mathrm{sec}$. In between the polycarbonate material comes in contact with the heated front mass and microstructure and plastic deformation of the polycarbonate takes place. When heated front mass touches the polycarbonate time starts to count and after $4 \mathrm{sec}$ the vibration frequency $11.9 \mathrm{kHz}$ is applied for $4 \mathrm{sec}$ and the after $2 \mathrm{sec}-$ ond of period the pressure has been taken off from the polycarbonate. At the same procedure was followed for the frequency $10.3 \mathrm{kHz}$.

The final step of the experiment is demolding - the mold is withdraw and the polycarbonate is being cooldown till the ambient temperature micro relief of the master structure has been transferred on the surface of the polycarbonate.

The structural scheme of mechanical hot imprint process is represented in Fig. 13. 


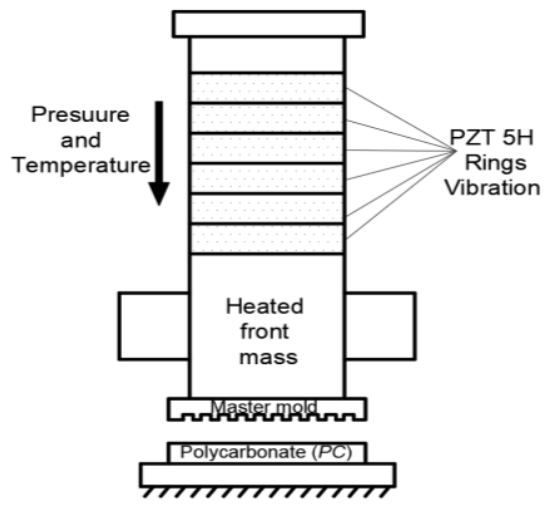

Fig. 13 Structural scheme of hot imprint process with ultrasonic excitation (pressure, temperature, sinusoidal force (Vibrations))

The same experimental procedure is followed at frequency of $10.3 \mathrm{kHz}$. Also, the results oscillations are observed. For the whole experiment parameters like temperature, pressure and time for the printing was kept constant. The Experimental matrix of the process of mechanical hot imprint, with usage of high frequency excitation is presented in the Table 2.

Table 2

Experimental matrix of the process of mechanical hot imprint, with usage of high frequency excitation

\begin{tabular}{|c|c|c|}
\hline Sonotrode & Without frequency & With frequency \\
\hline Impressing time $t, \mathrm{~s}$ & 10 & 10 \\
\hline Pressure $P, \mathrm{~N}$ & 5000 & 5000 \\
\hline $\begin{array}{c}\text { Vibration frequency } \\
f, \mathrm{kHz}\end{array}$ & 0 & 10.3 and 11.9 \\
\hline Temperature $T,{ }^{\circ} \mathrm{C}$ & 150 & 150 \\
\hline
\end{tabular}

Also, the material properties of the polycarbonate (PC) are presented in the Table 3.

Table 3

Material properties of the Polycarbonate (PC)

\begin{tabular}{|c|c|}
\hline Property & Polycarbonate (PC) \\
\hline Density $\rho$ & $1.20-1.22 \mathrm{~g} / \mathrm{cm}^{3}$ \\
\hline Young's modulus $E$ & $2.0-2.4 \mathrm{GPa}$ \\
\hline Poisson's ratio $v$ & 0.37 \\
\hline Glass transition temperature $T g$ & $147^{\circ} \mathrm{C}$ \\
\hline
\end{tabular}

\section{Replicas quality examination techniques}

The nature of replicas was assessed utilizing an aberrant optical technique - estimation of the diffraction efficiency. Periodical microstructures are made from optic materials; therefore, optical assessment methods are utilized for quality examination.

Diffraction efficiency of grating, created by hot imprint process on the surface of polycarbonate is one of the parameters, which determines the quality of microstructure. Gratings are created by using hot imprint process with and without high frequency excitation and during the quality investigation, diffraction efficiencies were measured on purpose to find microstructure of best possible optical quality, as well determine whether high frequency excitation and other process parameters during the process affect this parameter. Process parameters include temperature, excitation frequency, force of mechanical load and duration of hot imprint process, the purpose is to determine the collection of parameters, which influences the diffraction efficiency most positively. The principle of the distributed diffraction efficiencies is presented in the Fig. 14.

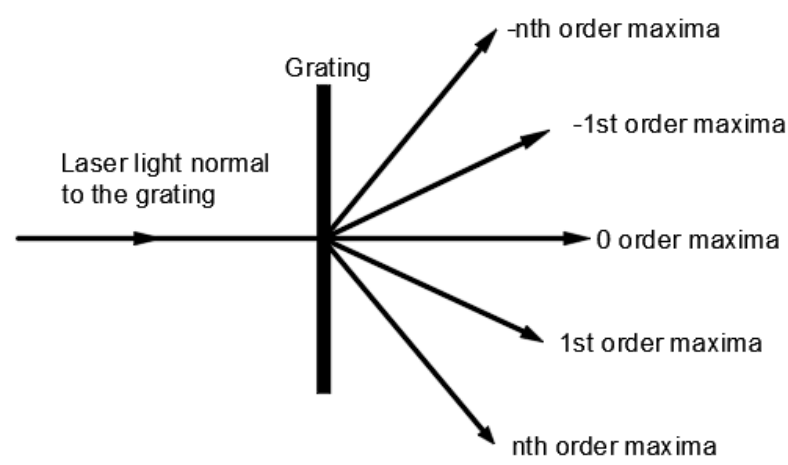

Fig. 14 Principle of the grating distribution of maxima

Optical investigation setup and simplified scheme is presented in the Fig. 15, used in order to determine diffraction efficiencies, consists of three major parts: sample, photodiode, ammeter. The laser ( $\lambda=632 \mathrm{~nm}$ Red $)$ and photodiode BPW-34 were used in order to measure diffraction efficiency. Scheme is connected to tester.

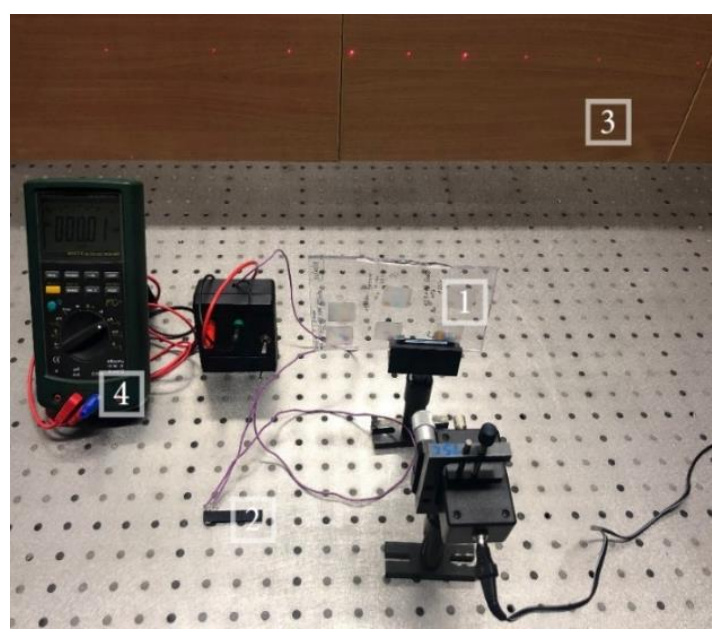

Fig. 15 Measurement of diffraction efficiency: sample 1 photodiode 2 connected to ammeter 4 , distribution of diffraction maxima 3

The laser beam is coordinated to the microstructure. As the beam goes through the microstructure, it is being diffracted into specific measure of maxima, which reach the photodiode. The electric flow, which goes through photodiode is enlisted with ammeter. Electrical flow, which goes through the photodiode sprightly, relies upon the lighting, in this way no extra figurines are required so as to think about outcomes. Diffraction maximas are dissipated, so they are estimated by changing the situation of photodiode so wanted maxima would go through photodiode.

In order to identify the quality of the printed microstructure on the polycarbonate material optical microscope "NICON Eclipse LV 150" with CCD camera was used. The optical microscope, often referred to as the light microscope, is a type of microscope that commonly uses visible light and a system of lenses to magnify images of small objects. The optical microscope is used to find out the 
images of magnified surface view, by allowing bubbles of residual gas defect and distortions.

The experimental setup of the optical microscope image analysis is presented in the Fig. 16.

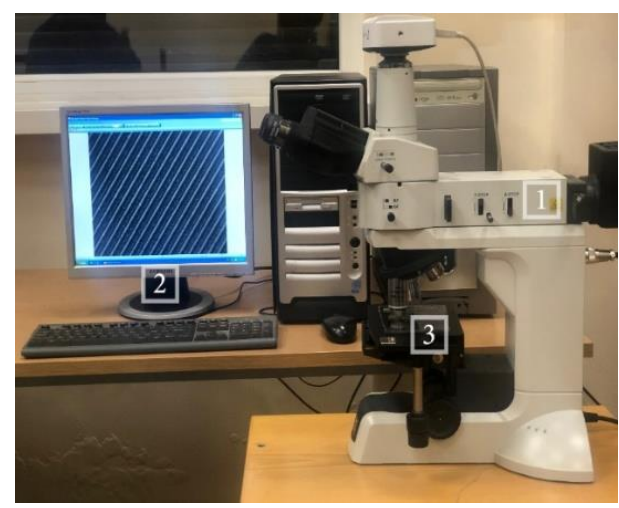

Fig. 16 Optical microscope: optical microscope connected to $\mathrm{PC} 1, \mathrm{PC}$ for reading 2 , specimen 3

\section{Results and discussion}

During the hot imprinting, the obtained printed microstructure on the polycarbonate is presented on the Fig. 17.

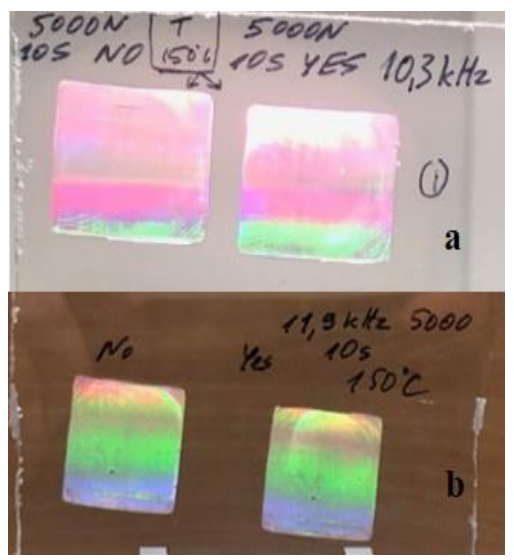

Fig. 17 a) Printed microstructure during hot imprinting $5000 \mathrm{~N}$ pressure, $150{ }^{\circ} \mathrm{C}$ temperature, time $10 \mathrm{sec}$, and $10.3 \mathrm{kHz}$ frequency and b) $5000 \mathrm{~N}$ pressure, $150^{\circ} \mathrm{C}$ temperature, time $10 \mathrm{sec}$, and $11.9 \mathrm{kHz}$ frequency

Also, there were experiments performed with the lower pressure and temperature with the less time period of the printing and the obtained result is presented in the Fig. 18.

From the Fig. 17 and Fig. 18 it is possible to state that frequency, temperature, pressure and time for applied pressure and vibrations also effects the quality of the printed structure.

From Fig. 19 it can be possible to state that the with the higher frequency it is possible to obtain similar printing like master mould on the other side without frequency the printing quality of the microstructure is poor. The magnified views obtained from the optical microscope of the grating surfaces are presented in the Fig. 19. Also, it is possible to see the defects produced during the printing process by using this method.
The images obtained from the optical microscope clearly shows that without frequency the quality of the printed microstructure is not like the master structure.

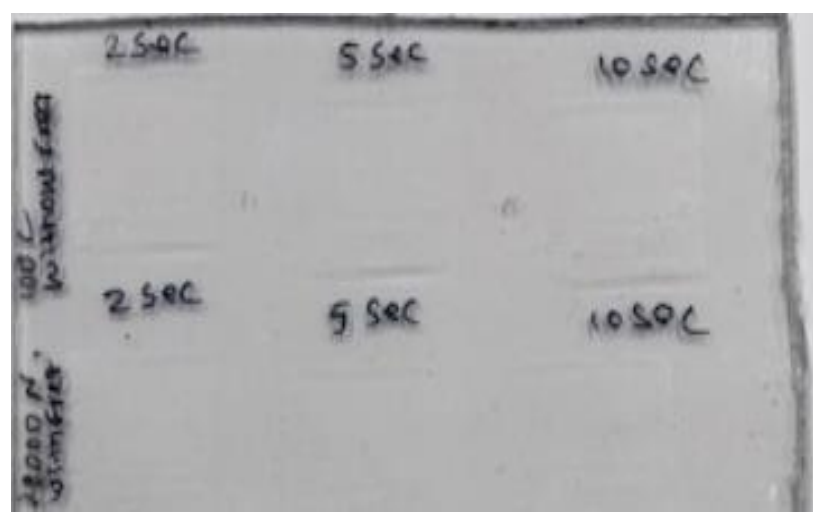

Fig. 18 Printed microstructures during hot imprinting: $4000 \mathrm{~N}$ pressure, $100^{\circ} \mathrm{C}$ temperature, time 2,5 and 10 seconds, with and without frequency

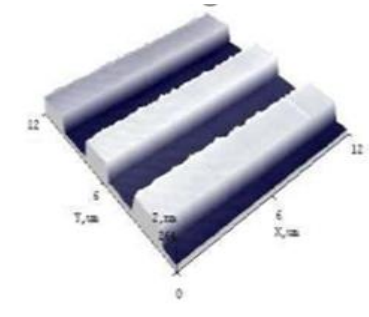

a

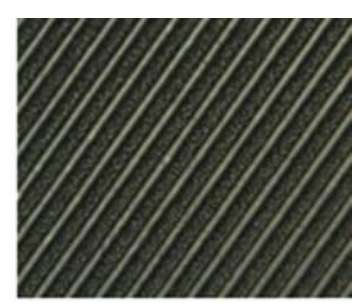

b

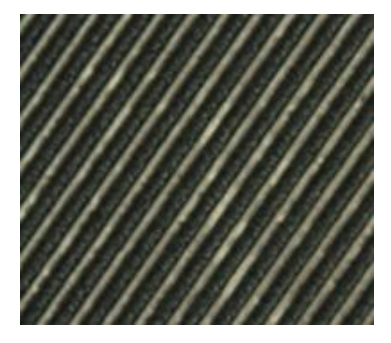

c

Fig. 19 Optical microscope images: a) AFM image of master structure and optical microscope images of its replica obtained using thermal imprinting with and without vibration, b) microstructure made without vibration; c) microstructure made with vibration

Diffraction efficiency of +1 and - 1 maxima is the most significant criteria, which decides optical quality of the periodical grating. Higher estimations of these maxima are emphatically alluring in numerous applications. The principle consideration is being paid to these maxima.

The obtained results from the experiment of the diffraction efficiency are presented in the Fig. 20.

Measurement of diffraction maxima results (Fig. 20) show that the high frequency vibration excitation by using sonotrode as a basis of vibration during the process of mechanical hot imprint increases the diffraction efficiency of the first order maximum 2 times. The obtained values for the diffraction efficiency for $11.09 \mathrm{kHz}(43.32 \%)$, $10.03 \mathrm{kHz}(39.76 \%)$, and without any frequency is $32.36 \%$. So, when comparing with microstructure created without vibration has almost the difference of the $29 \%$ values of diffraction efficiency. So, it is clearly showing that the quality of replica is much better with the higher vibrations. Results 
show a positive trend for future research, when having purpose to get periodic microstructure with higher diffraction efficiency.

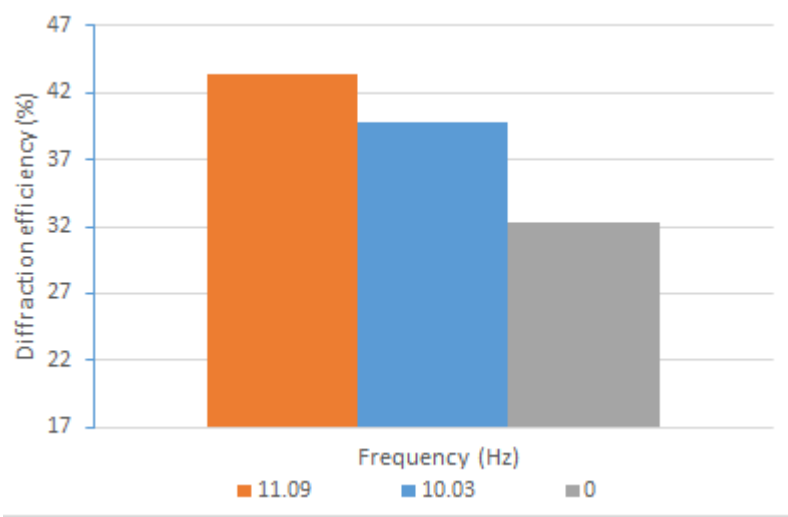

Fig. 20 Results of the diffraction efficiency comparison of diffraction efficiency with respect to frequency $(\mathrm{kHz})$ when time $10 \mathrm{~s}$ and temperature $150^{\circ} \mathrm{C}$

\section{Conclusions}

1. Numerical simulation of eigenfrequencies of sonotrode showed, that resonance frequency obtained from the numerical simulation was $11.22 \mathrm{kHz}$ and the resonance frequency obtained from the experiment was $12.5 \mathrm{kHz}$. Also, the desire shape deformation of the numerical model is achieved at $11.22 \mathrm{kHz}$. It means the designed model cor responds with the experimental results and there is only difference of the $10.7 \%$ in the resonance frequency.

2. Measurement of the diffraction efficiency shows that the achieved results for the diffraction efficiency for $11.09 \mathrm{kHz}(43.32 \%), 10.03 \mathrm{kHz}(39.76 \%)$ and without any excitation is very low $32.36 \%$. it means by using vibration the quality of the printed microstructure has been improved.

3 . From the optical microscopy image it is clear that by applying the higher vibration it is possible to achieve the better quality of the replicas and the temperature pressure and the time for the printing also effects the quality of the printed microstructure.

\section{Acknowledgement}

This research was funded by a grant S-MIP-17-102 from the Research Council of Lithuania.

\section{References}

1. Worgull, M.; Hétu, J. F.; Kabanemi, K. K.; Heckele, M. 2006. Modeling and optimization of the hot embossing process for micro- and nanocomponent fabrication, Microsystem Technologies 12: 947-952. https://doi:10.1007/s00542-006-0124-0.

2. He, Y.; Fu, J. Z.; Chen, Z. C. 2007.Research on optimization of the hot embossing process, Journal of Micromechanics and Microengineering 17: 2420. https://doi:10.1088/0960-1317/17/12/005.

3. Nian, S. C.; Tsai, T. H.; Huang, M. S. 2016. Novel inductive hot embossing for increasing micromolding efficiency, International Communications in Heat and Mass Transfer 70: $38-46$. https://doi.org/10.1016/j.icheatmasstransfer.2015.11.005.
4. Krauss, P. R.; Chou, S. Y. 1997. Nano-compact disks with $400 \mathrm{Gbit} / \mathrm{in} 2$ storage density fabricated using nanoimprint lithography and read with proximal probe, Applied Physics Letters 71: 3174-3176. http://dx.doi.org/10.1063/1.120280.

5. Jaszewski, R. W. et al. 1998. Hot embossing in polymers as a direct way to pattern resist, Microelectronic Engineering 41-42: 575-578. https://doi.org 10.1016/S0167-9317(98)00135-X.

6. Mekaru, H.; Goto, H.; Takahashi, M. 2007. Development of ultrasonic micro hot embossing technology, Microelectronic Engineering 84: 1282-1287. https://doi.org 10.1016/j.mee.2007.01.235.

7. Hirai, Y.; Yoshida, S.; Takagi, N. 2003. Defect analysis in thermal nanoimprint lithography, Journal of Vacuum Science and Technology B, 21(6): 2765-2770. http://dx.doi.org/10.1116/1.1629289.

8. Narijauskaitè, B. et al. 2011. High-frequency excitation for thermal imprint of microstructures into a polymer, Experimental Techniques (published online: 11 APR 2011). http://dx.doi.org/10.1111/j.1747-567.2011.00724.x/.

9. Liu, C. et al. 2010. Deformation behavior of solid polymer during hot embossing process, Microelectronic Engineering 87: 200-207. http://dx.doi.org/10.1016/j.mee.2009.07.014.

10. Hu, X. F. 2005. Research on the Equipment for Hot Embossing and Related Experiments. Master thesis.

11. Yoshihiko, H.; Yoshida, S.; Nobuyuki, T. 2003. Defect analysis in thermal nanoimprint lithography, Journal of Vacuum Science Technology B, 21: 2765-2770. http://dx.doi.org/10.1116/1.1629289.

12. Li, J. M.; Liu, C.; Peng, J. 2008. Effect of hot embossing process parameters on polymer flow and microchannel accuracy produced without vacuum, Journal of Materials Processing Technology 207: 163-171. http://dx.doi.org/10.1016/j.jmatprotec.2007.12.062

13. Yao, D. G.; Vinayshankar, L. V.; Byung, K. 2005. Study on sequeezing Flow during nonisothermal embossing of polymer microstructure, Journal Polymer Engineering and Science 45: 652-660. http://dx.doi.org/10.1002/pen.20322.

14. Lin, C. R.; Chen, R. H.; Chen, C. H. 2003. Preventing non-uniform shrinkage in ope-die hot embossing of PMMA microstructures, Journal Material of Processing Technology 140: 173-178. http://dx.doi.org/10.1016/S0924-0136(03)00709-X.

15. Benatar, A.; Gutowski, T.G. 1989. Ultrasonic welding of PEEK graphite APC-2 composites, Polymer Engineering and Science 29(23): 1705-1721. http://dx.doi.org/10.1002/pen.760292313.

16. Nonhof, C. J.; Luiten, G. A. 1996. Estimates for process conditions during the ultrasonic welding of thermoplastics, Polymer Engineering and Science 36: 11771183. http://dx.doi.org/10.1002/pen.10511.

17. Liu, S. J. et al. 1998. Development of weldability diagrams for ultrasonic welding of thermoplastics in farfield, Plastic Rubber Composite Processing and Applications 27(6): 279-286.

18. Liu, S. J.; Chang, I. T.; Hung S. W. 2001. Factors affecting the joint strength of ultrasonically welded polypropylene composites, Polymer Composites 22(1): 132141. 
http://dx.doi.org/10.1002/pc.10525.

19. Liu, J. S.; Dung, Y. T. 2005. Hot embossing precise structure onto plastic plates by ultrasonic vibration, Polymer Engineering and Science 45: 915-925. http://dx.doi.org/10.1002/pen.20357.

20. Yang, F., Murugan, R., Ramakrishna, S., Wang, X., Ma, Y.-X., and Wang, S. 2004. Fabrication of nanostructured porous PLLA scaffold intended for nerve tissue engineering, Biomater 25: 1891-1900.

21. Smith, L. A., Liu, X., Ma, P. X. 2008. Tissue engineering with nano-fibrous scaffolds, Soft Matter 4(11): 2144-2149. https://doi.org 10.1039/b807088c,

22. Weilbaecher, C. R., Hossain, M., Gangopadhyay, S., and Grant, S. 2007. Development of a novel nanomaterial-based optical platform for a protease biosensor, Proc. SPIE, vol. 6759.

23. Naeemi, A.; Meindl, J. D. 2009. Carbon nanotube interconnects. Ann. Rev. Mater. Res. 39: 255-275.

24. Nanostructured materials in information storage. MRS Bull. 33: 831-834. https://doi.org/10.1146/annurev-matsci-082908145247.

25. Zhang, Y., Lu, J., Shimano, S., Zhou, H.; Maeda, R. 2007. Nanoimprint of proton exchange membrane for MEMS-based fuel cell application, Proc. 6th Int. IEEE Conf. on Polymers and Adhesives in Microelectronics and Photonics p.p. 91-95. https://doi.org 10.1109/POLYTR.2007.4339145.

26. Zhang, Y., Lu, J., Wang, Q., Takahashi, M., Itoh, T.; Maeda, R. 2009. Nanoimprint of polymer electrolyte membrane for micro direct methanol fuel cell application. ECS Trans. Micro Power Sources 16: 11-17.

27. Yule, A. J.; Al-Suleimani, Y. 2000. On droplet formation from capillary waves on a vibrating surface, Mathematical physics and Engineering sciences 456: 1069-1085. https://doi.org/10.1098/rspa.2000.0551.

28. Zhang, A., et al. 2009. Rapid concentration of particle and bioparticle suspension based on surface acoustic wave, Applied Acoustics 70(8): 1137-1142. https://doi.org 10.1117/12.879148.

29. Kondoh, J., et al. 2009. Development of temperaturecontrol system for liquid droplet using surface Acoustic wave devices, Sensors and Actuators A: Physical 149(2): 292-297. https://doi.org 10.1016/j.sna.2008.11.007.

30. Lomonosov, A. M.; Hess, P. 2008. Nonlinear surface acoustic waves: Realization of solitary pulses and fracture, Ultrasonics 48(6-7): 482-487.

31. Alvarez, M.; Friend, J. R.; Yeo, L. Y. 2008. Surface Vibration induced spatial ordering of periodic polymer patterns on a substrate, Langmuir 24: 10629-10632. https://doi.org/10.1021/la802255b.
32. Changliang, X.; Mengli, W. 2005. Stability analysis of the rotor of ultrasonic motor driving fluid directly, Ultrasonics 43(7): 596-601.

https://doi.org 10.1111/j.1747-1567.2011.00724.x.

33. Ming, Y., et al. 2005. Design and evaluation of linear ultrasonic motors for a cardiac compression assist device, Sensors and Actuators A: Physical 119(1): 214220.

https://doi.org 10.1016/j.sna.2004.09.005.

Šakalys, R.; Janušas, G.; Palevičius, A.; Čekas, E.; Jūrènas, V.; Sodah, A. 2016. Microstructures replication using high frequency excitation, Microsystem technologies. Berlin: Springer p. 1-13.

34. Goldfarb, M.; Celanovic, N. 1997. Modeling piezoelectric stack actuators for control of micromanipulation, Control Systems, IEEE 17: 69-79. http://dx.doi.org/10.1109/37.588158.

35. Palevičius, A., et al. 2008. Digital holography for analysis of mechatronic systems, Proceedings of the 7th International Conference Vibroengineering 2008, October 9-11, Kaunas, Lithuania, p. 78-82. http://dx.doi.org/10.5755/j01.mech.21.2.8886.

36. Piefort, V.; Preumont, A. 2001. Finite Element Modeling of Piezoelectric Structures. Samtech User's Conference.

A. Sodah, A. Palevicius, G. Janusas, P. Palevicius, Y. Patel

\section{NUMERICAL AND EXPERIMENTAL INVESTIGATION OF SONOTRODE FOR FORMATION OF PIEZOCOMPOSITE FUNCTIONAL ELEMENTS}

S u m m a r y

The paper is dedicated to analysis, practical exploitation of sonotrode, whose fundament is multilayer actuator in experiments of mechanical hot imprint. The goal is to compare the quality of microstructures, created by using vibration based on multilayer actuator. Numerical modelling and experimental analysis is performed in order to find resonant frequency of the sonotrode. Having operating frequency, sonotrode applied in mechanical hot imprint process. Microstructures are created on the surface of polycarbonate; the only process variable is vibration. Two types of microstructure quality measurements are performed: measurement of diffraction efficiency, optical microscopy in order to examine quality of replica.

Keywords: sonotrode; mechanical vibrations; micro hydraulic devices, periodic microstructure.

Received May 07, 2019

Accepted November 21, 2019 